\title{
HUBUNGAN ANTARA KUALITAS BIDAN DALAM PELAYANAN ANTENATAL CARE TERHADAP PERSEPSI IBU HAMIL
}

\author{
Citra Hadi Kurniati \\ ${ }^{1}$ Prodi Kebidanan, Universitas Muhammadiyah Purwokerto dan citrahadi85@gmail.com
}

\begin{abstract}
ABSTRAK
Bidan memegang peranan yang penting dalam proses pelayanan kesehatan terutama pelayanan pemeriksaan kehamilan atau Antenatal care (ANC). Kualitas pelayanan bidan menentukan keberhasilan proses pelayanan tersebut. Persepsi ibu hamil ketika datang memeriksakan kehamilan berhubungan dengan ketersediaannya untuk kembali lagi melakukan pemeriksaan Antenatal Care. Penelitian ini bertujuan untuk mengetahui kualitas bidan dalam pelayanan ANC terhadap persepsi ibu hamil. Jenis penelitian menggunakan penelitian analitik observasional, dimana peneliti diarahkan untuk menjelaskan suatu keadaan atau situasi. Pendekatan waktu yang digunakan adalah cross sectional. Analisis dilakukan untuk menguji kualitas bidan dalam memberikan pelayanan ANC terhadap persepsi ibu hamil. Analisis data dalam penelitian dengan variabel berskala ordinal dengan statistika non-parametrik. Pengujian hipotesis mengunakan Uji Chi Square. Hasil penelitian menunjukkan bahwa tidak ada hubungan antara kualitas bidan terhadap persepsi ibu hamil dengan nilai $p$ valeu $>0,05$ dengan $X^{2}$ hitung sebesar 0,325. Kesimpulan dari penelitian ini yaitu tidak terdapat hubungan antara kualitas bidan dalam memberikan pelayanan ANC terhadap persepsi ibu hamil
\end{abstract}

Kata Kunci : kualitas bidan dan persepsi

\section{ABSTRACT}

Midwives play an important role in the process of health care, especially antenatal care services (ANC). The quality of midwife services determines the success of the service process. The perception of pregnant women when they come for a pregnancy is related to their availability to return to Antenatal Care examination. This study aims to determine the quality of midwives in ANC services on the perception of pregnant women. This type of research uses observational analytic research, where researchers are directed to explain a situation or situation. The time approach used is cross sectional. Analysis was conducted to test the quality of midwives in providing ANC services to the perception of pregnant women. Analysis of the data in research with ordinal and scale variables is non-parametric statistics. Hypothesis testing using the Chi Square Test. The results showed that there was no relationship between the quality of midwives on perceptions of pregnant women with a $p$ value of valeu $>0.05$ with an $X \times$ count of 0.325. The conclusion of this study is that there is no relationship between the quality of midwives in providing ANC services to the perception of pregnant women

Keywords: quality of midwive and perception

\section{PENDAHULUAN}

Bidan merupakan seorang wanita yang telah mengikuti dan menyelesaikan pendidikan kebidanan yang telah diakui oleh pemerintah dan lulus ujian sesuai dengan persyaratan yang berlaku dan diberi izin secara sah untuk melaksanakan praktek. Bidan memberikan pelayanan kebidanan sesuai dengan kewenangan yang berlaku sesuai dengan permenkes tentang registrasi dan praktek bidan.

Bidan mempunyai tugas penting dalam siklus kehidupan perempuan untuk menjaga kelangsungan kesehatan selama proses reproduksinya. Tugas bidan mulai dari persiapan menjadi orang tua, antenatal care, intranatal, postnatal, asuhan bayi baru lahir, gangguan reproduksi serta keluarga berencana.

Bidan memberikan asuhan dan konseling selama kehamilan yaitu memberikan asuhan antenatal care bermutu tinggi untuk mengoptimalisasi kesehatan ibu dan janinnya selama kehamilan meliputi deteksi dini kehamilan atau rujukan dari komplikasi tertentu. Antenatal care merupakan pemeriksaan yang dilakukan untuk memeriksa keadaan ibu dalam upaya deteksi dini kehamilannya. Dalam memberikan pelayanan antenatal care, ibu mendapatkan pelayanan sesuai dengan kualitas bidan yang diberikan. Kualitas tersebut yang menentukan apakah ibu mau kembali untuk memeriksakan lagi ke tempat bidan tersebut.

Pelayanan ANC berkualitas mempunyai peranan yang penting dalam upaya menurunkan angka kematian ibu dan bayi, karena melalui pelayanan yang professional dan berkualitas, ibu hamil memperoleh pendidikan tentang cara menjaga diri agar tetap sehat, serta meningkatkan kesadaran dan pengetahuan tentang kemungkinan adanya resiko atau terjadinya komplikasi dalam kehamilan, sehingga dapat dicapai kesehatan yang optimal dalam 
menghadapi persalinan dan nifasnya (Hendarwan, dkk 2018).

Pelayanan kesehatan yang bermutu adalah pelayanan yang dilaksanakan oleh tenaga kesehatan yang kompeten, memegang teguh falsafah, dilandasi oleh etika dan kode etik serta didukung sarana dan prasarana yang memadai (Hendarwan, dkk 2018). Kualitas bidan meliputi kemampuan melakukan pelayanan, ketanggapan untuk melayani dengan baik, kesopanan dalam melakukan pemeriksaan dan perhatian terhadap individu.

Pelayanan antenatal oleh bidan yang dilakukan dalam waktu singkat akan mempengaruhi kualitas pelayanan sehingga kurangnya komunikasi dan penjelasan tentang kesehatan. Bidan lebih memprioritaskan hanya pemeriksaan fisik saja, tidak diikuti dengan upaya pemberian pendidikan kesehatan kepada ibu (Arifin, 2005).

Berdasarkan uraian latar belakang diatas maka peneliti akan melakukan penelitian dengan judul "Hubungan antara kualitas bidan dalam pelayanan Antenatal Care terhadap Persepsi Ibu Hamil".

\section{TINJAUAN PUSTAKA \\ Persepsi}

Persepsi adalah pengalaman tentang objek, peristiwa, atau hubungan-hubungan yang diperoleh dengan menyimpulkan informasi dan menafsirkan pesan. Proses terjadinya persepsi tergantung dari pengalaman masa lalu dan pendidikan yang diperoleh individu. Persepsi adalah proses yang digunakan individu mengelola dan menafsirkan kesan indera mereka dalam rangka memberikan makna kepada lingkungan mereka. Meski demikian apa yang dipersepsikan seseorang dapat berbeda dari kenyataan yang obyektif. Menurut Notoatmodjo (2005), ada banyak faktor yang akan menyebabkan stimulus masuk dalam rentang perhatian seseorang. Faktor tersebut dibagi menjadi dua bagian besar yaitu faktor eksternal dan faktor internal. Faktor eksternal adalah faktor yang melekat pada objeknya, sedangkan faktor internal adalah faktor yang terdapat pada orang yang mempersepsikan stimulus tersebut.

Menurut Edberg (2007), Health Belief Model (HBM) merupakan teori yang paling luas digunakan. HBM dicetuskan pada tahun 1950-an berkat penelitian psikolog sosial dari U.S Public Health Service (USPHS) yakni Godfrey Houchbaum, Irwin Rosenstock, dan Stephen Kegeles. HBM dalam promosi kesehatan harus memperhatikan komponen-komponen atau konstruksi yang merupakan pengungkit bagi faktor yang mempengaruhi perilaku. Komponenkomponen model hubungan kesehatan dengan kepercayaan (HBM) adalah:
1. Persepsi kerentanan. Derajat risiko yang dirasakan seseorang terhadap masalah kesehatan.

2. Persepsi keparahan. Tingkat kepercayaan seseorang bahwa konsekuensi masalah kesehatan yang akan menjadi semakin parah.

3. Persepsi manfaat. Hasil positif yang dipercaya seseorang sebagai hasil dari tindakan.

4. Persepsi hambatan. Hasil negatif yang dipercayai sebagai hasil dari tindakan.

5. Petunjuk untuk bertindak. Peristiwa eksternal yang memotivasi seseorang untuk bertindak.

6. Efikasi diri. Kepercayaan seseorang akan kemampuannya dalam melakukan tindakan.

\section{Kualitas Pelayanan}

Pengertian atau makna atas konsep kualitas telah diberikan oleh banyak pakar dengan berbagai sudut pandang yang berbeda, sehingga menghasilkan definisi-definisi yang berbeda pula. Goesth dan Davis yang dikutip Tjiptono, mengemukakan bahwa kualitas diartikan "sebagai suatu kondisi dinamis dimana yang berhubungan dengan produk, jasa, manusia, proses dan lingkungan yang memenuhi atau melebihi harapan.”(Tjiptono, 2005)

Pelayanan publik/umum merupakan salah satu fungsi utama dari pemerintah. Pemerintah berkedudukan sebagai lembaga yang wajib memberikan atau memenuhi kebutuhan masyarakat. Pelayanan merupakan terjemahan dari istillah service dalam bahasa Inggris yang menurut Kotler yang dikutip Tjiptono, yaitu berarti "setiap tindakan atau perbuatan yang dapat ditawarkan oleh satu pihak ke pihak yang lain, yang pada dasarnya bersifat intangible (tidak berwujud fisik) dan tidak menghasilkan kepemilikan sesuatu".(Tjiptono, 2005). Pada dasarnya kualitas pelayanan umum itu meliputi, sebagai berikut:

1. Aspek kemampuan sumber daya manusia yang terdiri dari keterampilan, pengetahuan, dan sikap diupayakan untuk ditingkatkan, maka hal tersebut akan mempengaruhi pelaksanaan tugasnya, dan apabila pelaksanaan tugas dilakukan secara lebih profesional, maka akan menghasilkan kualitas pelayanan yang lebih baik.

2. Apabila sarana dan prasarana dikelola secara tepat, cepat dan lengkap, sesuai dengan kebutuhan atau tuntutan masyarakat, maka hal tersebut akan menghasilkan kualitas pelayanan yang lebih baik.

3. Prosedur yang dilaksanakan harus memperhatikan dan menerapkan ketepatan prosedur, kecepatan prosedur, serta kemudahan prosedur, sehingga dapat meningkatkan kualitas pelayanan yang lebik baik dari sebelumnya. 
4. Bentuk jasa yang diberikan kepada masyarakat dapat berupa kemudahan dalam memperoleh informasi, ketepatan, kecepatan pelayanan, sehingga kualitas pelayanan yang lebih baik akan dapat diwujudkan.

Jadi prsoses penentuan suatu kualitas pelayanan yang diberikan merupakan penilaian dari penerima jasa berdasarkan sudut pandang dan persepsi pelanggan atas jasa pelayanan yang didapatkan. Persepsi penilaian pelanggan terhadap pelayanan yang diberikan merupakan penilaian menyeluruh dari suatu penilaian pelayanan yang diberikan sehingga dapat dikatakan bahwa suatu pelayanan yang berkualitas adalah pelayanan yang berdasarkan pada kepuasan pelanggan. Jika suatu kepuasan tercipta maka persepsi suatu pelayanan yang berkualitas akan tumbuh.

\section{Antenatal Care}

Pelayanan antenatal merupakan pelayanan kesehatan oleh tenaga kesehatan terlatih untuk ibu selama masa kehamilannya, dilaksanakan sesuai dengan standar pelayanan antenatal yang ditetapkan dalam Standar Pelayanan Kebidanan (SPK) (Depkes, 2010).

Pelayanan antenatal adalah pelayanan kesehatan oleh tenaga professional (dokter spesialis kebidanan, dokter umum, bidan, pembantu bidan dan perawat bidan) untuk ibu selama masa kehamilannya, sesuai dengan standar minimal pelayanan antenatal.

Menurut Wiknjosastro (2005), tujuan pengawasan wanita hamil ialah menyiapkan ia sebaik-baiknya fisik dan mental, serta menyelamatkan ibu dan anak dalam kehamilan, persalinan dan masa nifas, sehingga keadaan postpartum sehat dan normal, tidak hanya fisik akan tetapi juga mental, ini berarti dalam antenatal care harus diusahakan agar :

a. Wanita hamil sampai akhir kehamilan sekurang kurangnya harus sama sehatnya atau lebih sehat.

b. Adanya kelainan fisik atau psikologi harus ditemukan dini dan diobati.

c. Wanita melahirkan tanpa kesulitan dan bayi yang dilahirkan sehat pula fisik dan mental.

Menurut Departemen Kesehatan RI (2002) tujuan pelayanan antenatal adalah sebagai berikut :

a. Memantau kemajuan kehamilan untuk memastikan kesehatan ibu dan tumbuh kembang janin.

b. Meningkatkan serta mempertahankan kesehatan fisik, mental, sosial ibu dan janin.

c. Mengenali secara dini adanya ketidaknormalan atau komplikasi yang mungkin terjadi selama hamil, termasuk riwayat penyakit secara umum, kebidanan dan pembedahan. d. Mempersiapkan persalinan cukup bulan, melahirkan dengan selamat ibu maupun bayi dengan trauma seminimal mungkin.

e. Mempersiapkan ibu agar masa nifas berjalan normal dan pemberian ASI Eksklusif.

f. Mempersiapkan peran ibu dan kelurga dalam menerima kelahiran bayi agar dapat tumbuh kembang secara normal.

g. Menurunkan angka kesakitan dan kematian ibu dan perinatal.

\section{Fungsi Antenatal}

Menurut Fitrihanda (2012), fungsi antenatal adalah sebagai berikut :

a. Promosi kesehatan selama kehamilan melalui sarana dan aktifitas pendidikan.

b. Melakukan screning, identifikasi wanita dengan kehamilan risiko tinggi dan merujuk bila perlu.

c. Memantau kesehatan selama hamil dengan usaha mendeteksi dan menangani masalah yang terjadi.

Perilaku antenatal care penting untuk mengetahui dampak kesehatan bayi dan si ibu sendiri, sementara faktanya masih banyak ibuibu yang menganggap kehamilan sebagai hal yang biasa, alamiah dan kodrati, mereka merasa tidak perlu memeriksakan kehamilannya secara rutin ke Bidan atau tenaga kesehatan sehinga menyebabkan tidak terdeteksinya faktor resiko tinggi yang mungkin dialami oleh mereka.

\section{Standar Pelayanan Antenatal}

Menurut Clinical Practice Guidelines yang dikutip oleh Nurmawati (2010). Standar adalah keadaan ideal atau tingkat pencapaian tertinggi dan sempurna sebagai batas penerimaan minimal. Standar pelayanan kebidanan dapat digunakan untuk menentukan kompetensi yang diperlukan oleh bidan dalam menjalankan praktek sehari-hari.

Menurut Dewi dan Sunarsih (2011) dengan melakukan ANC, kehamilan dan persalinan akan berakhir dengan hal-hal sebagai berikut :

1. Ibu dalam kondisi selamat selama kehamilan, persalinan, dan nifas tanpa trauma fisik maupun mental yang merugikan.

2. Bayi dilahirkan sehat, baik fisik maupun mental.

3. Ibu sanggup merawat dan memeberikan ASI kepada bayinya.

4. Suami istri telah ada kesiapan dan kesanggupan untuk mengikuti keluarga berencana setalah kelahiran bayinya.

\section{METODE}

Penelitian ini menggunakan penelitian analitik observasional, dengan pendekatan waktu yang digunakan adalah cross sectional yaitu penelitian untuk mempelajari dinamika korelasi 
antara variabel dependen dan independen serta pengumpulan data dilakukan sekaligus dalam waktu yang bersamaan dan pengukurannya hanya dilakukan sekali saja (Sugiyono, 2010). Populasi dalam penelitian ini yaitu seluruh ibu hamil yang ada di puskesmas sokaraja . Sampelnya yaitu ibu hamil yang di desa sokaraja lor, dengan teknik pengambilan sampelnya menggunakan teknik accidental sampling yaitu pengambilan sampel yang dilaksanakan dalam waktu tertentu. Variabel Independent : persepsi ibu hamil dan Variabel dependent : kualitas bidan dalam pemeriksaan antenatal care. Analisis menggunakan chi Square $\left(X^{2}\right)$.

\section{HASIL DAN PEMBAHASAN}

Penelitian ini dilakukan di Desa Sokaraja Lor Kecamatan Sokaraja. Desa Sokaraja Lor merupakan desa yang ada di Kecamatan Sokaraja yang memiliki 3 posyandu ibu hamil dengan jumlah total ibu hamil sebanyak 70 orang. Namun pada saat dilakukan penelitian jumlah responden ibu hamil yang datang hanya berjumlah 57 orang.

Hasil penelitian menunjukkan ibu hamil yang mempunyai persepsi cukup sebanyak 53 orang atau 92,9\%, sedangkan ibu hamil yang persepsinya kurang dan baik sebanyak 2 orang atau sekitar 3,5\%.

Ibu hamil yang mempunyai tingkat kualitas cukup sebanyak 53 orang atau sebanyak 92,9\%, sedangkan ibu hamil yang mempunyai tingkat kepuasan baik dan kurang sebanyak 2 orang atau sekitar 3,5\%.

Analisis bivariat dimaksudkan untuk mengetahui pengaruh masing-masing variabel independen dan dependen. Pengujian analisis bivariat dilakukan dengan menggunakan uji chisquare secara terperinci dapat dilihat sebagai berikut :

Tabel.1. Hubungan Persepsi Ibu Hamil Dengan Kualitas Pelayanan Bidan Di Desa Sokaraja Lor Kec. Sokaraja

\begin{tabular}{lcrrr}
\hline No & Persepsi & \multicolumn{3}{c}{ Kualitas Pelayanan } \\
\cline { 3 - 5 } & & Baik & Cukup & \multicolumn{1}{c}{ Kurang } \\
\hline 1. & Baik & 0 & 2 & 0 \\
2. & Cukup & 2 & 49 & 2 \\
3. & Kurang & 0 & 2 & 0 \\
\hline Jumlah & 2 & 53 & 2 \\
\hline \multicolumn{2}{c}{$\mathbf{X}^{2}$} & & & $0,325^{\text {a }}$ \\
\hline \multicolumn{2}{r}{$\boldsymbol{P}$ Value } & & & 0,988 \\
\hline
\end{tabular}

Berdasarkan analisis univariat menunjukan bahwa ibu hamil yang lebih banyak persepsinya berada di titik Cukup dengan prosentase $92,9 \%$ hasil uji statistik dengan chisquare menunjukan probabilitas (p) lebih besar dari $\alpha(0,000>0,05)$. Hal ini menunjukan tidak adanya pengaruh persepsi ibu hamil terhadap kualitas bidan dalam memberikan pelayanan Antenatal Care (ANC).

Menurut Notoatmodjo (2005), ada banyak faktor yang akan menyebabkan stimulus masuk dalam rentang perhatian seseorang. Faktor tersebut dibagi menjadi dua bagian besar yaitu faktor eksternal dan faktor internal. Faktor eksternal adalah faktor yang melekat pada objeknya, sedangkan faktor internal adalah faktor yang terdapat pada orang yang mempersepsikan stimulus tersebut.

Pengetahuan ibu hamil tentang kehamilan diperoleh salah satunya dari informasi yang diberikan oleh bidan pada saat pelayanan antenatal care. Hal ini dinyatakan dengan pendapat ibu hamil yang menunjukkan bahwa mereka sangat jarang bahkan tidak pernah mendapat penjelasan tentang kehamilan. Kurangnya penjelasan tersebut sehingga mempengaruhi persepsi ibu terhadap kualitas bidan. Sangat cepatnya pelayanan yang diberikan sehingga tidak memungkinkan tersedianya cukup waktu untuk menjelaskan pengetahuan tentang kehamilan. Kurangnya pemahaman akan pentingnya komunikasi kepada ibu sehingga bidan lebih memprioritaskan hanya pemeriksaan fisik.

Persepsi yang dibangun oleh pasien tidak tergantung dari kualitas yang diberikan oleh bidan tetapi dari berbagai faktor lain yang mendukung seperti pengalaman masa lalu, media dan orang lain.

Pada dasarnya harapan klien adalah perkiraan atau keyakinan klien tertang pelayanan yang diterimanya akan memenuhi harapannya. Sedangkan hasil kinerja akan dipersepsikan oleh klien. Kesimpulan yang dapat diambil dari beberapa pengertian di atas terdapat kesamaan pandangan bahwa kepuasan pelanggan/klien merupakan ungkapan perasaan puas apabila menerima kenyataan / pengalaman pelayanan memenuhi harapan klien. Kepuasan pelanggan adalah indikator utama dari standar suatu fasilitas kesehatan dan merupakan suatu ukuran mutu pelayanan kepuasan pelanggan yang rendah akan berdampak terhadap jumlah kunjungan yang akan mempengaruhi provitabilitas fasilitas kesehatan tersebut, sedangkan sikap karyawan terhadap pelanggan juga akan berdampak terhadap kepuasan pelanggan dimana kebutuhan pelanggan dari waktu ke waktu akan meningkat, begitu pula tuntutannya akan mutu pelayanan yang diberikan (Atmojo, 2006)

\section{Kualitas Pelayanan Bidan}

Berdasarkan analisis univariat menuunjukan bahwa ibu hamil yang mempunyai tingkat tingkat kualitas cukup sebanyak 53 orang atau sebanyak 92,9\%, sedangkan ibu hamil yang 
mempunyai tingkat kepuasan baik dan kurang sebanyak 2 orang atau sekitar 3,5\%.

Pelayanan umum baru dapat dikatakan berkualitas jika sesuai dengan harapan/keinginan atau kebutuhan penerima layanan, untuk dapat mengetahui apakah pelayanan umum yang diberikan pemerintah sesuai dengan keinginan atau kebutuhan masyarakat sebagai pengguna layanan, maka kualitas pelayanan umum harus diukur dan dinilai oleh masyarakat pengguna layanan. Hal tersebut sesuai dengan pendapat Lukman dan Sugiyanto, yang menyatakan bahwa: "Kualitas pelayanan berhasil dibangun, apabila pelayanan yang diberikan kepada pelanggan mendapatkan pengakuan dari pihakpihak yang dilayani.

Pengakuan terhadap keprimaan sebuah pelayanan, bukan datang dari aparatur yang memberikan pelayanan, melainkan datang dari pengguna jasa layanan.'(Lukman dan Sugianto, 2001). Hal senada pun diungkapkan oleh Tjiptono, yang menyebutkan bahwa: "Citra kualitas yang baik bukanlah berdasarkan sudut pandang atau persepsi penyedia jasa, melainkan berdasarkan sudut pandang atau persepsi pelanggan. Pelangganlah yang mengkonsumsi dan menikmati jasa, sehingga merekalah yang seharusnya menentukan kualitas pelayanan umum. Persepsi pelanggan terhadap kualitas jasa atau pelayanan merupakan penilaian menyeluruh atas keunggulan suatu pelayanan."(Tjiptono, 2005).

Jadi prsoses penentuan suatu kualitas pelayanan yang diberikan merupakan penilaian dari penerima jasa berdasarkan sudut pandang dan persepsi pelanggan atas jasa pelayanan yang didapatkan. Persepsi penilaian pelanggan terhadap pelayanan yang diberikan merupakan penilaian menyeluruh dari suatu penilaian pelayanan yang diberikan sehingga dapat dikatakan bahwa suatu pelayanan yang berkualitas adalah pelayanan yang berdasarkan pada kepuasan pelanggan. Jika suatu kepuasan tercipta maka persepsi suatu pelayanan yang berkualitas akan tumbuh.

\section{KESIMPULAN}

Kesimpulan dari penelitian ini yaitu tidak terdapat hubungan antara kualitas bidan dalam memberikan pelayanan ANC terhadap persepsi ibu hamil

\section{DAFTAR PUSTAKA}

Abdurrauf, 2000. Evaluasi kinerja instalasi gawat darurat RSU Banjar berdasarkan balanced scorecard, Tesis,UGM. Yogyakarta.

Al-Assaf. 2009. Mutu pelayanan kesehatan perspektif internasional, kedokteran EGC: Jakarta

Atmojo, Y,T., 2006. Mengukur Kepuasan Pelanggan dalam http://triatmojo.wordpress.com/2006/09/24/ mengukur-kepuasanpelanggan/

Arifin, A. 2005. Persepsi Ibu Hamil Tentang Antenatal Care dan Persalinan. Buletin Penelitian Sistem Kesehatan-Vol.8 No. 2 Desember 2005: 84-89

Depkes RI. 2009. Panduan pelaksanaan strategi making pregnancy safer dan child survival Jakarta

Dewi VNL, Sunarsih T. 2011. Asuhan kehamilan untuk kebidanan. Jakarta: salemba medika

Edberg M. 2007. Buku ajar kesehatan masyarakat: teori sosial dan perilaku. Jakarta: Buku Kedokteran: EGC.

Hendarwan,dkk. 2018. Kualitas Pelayanan Pemeriksaan Antenatal oleh Bidan di Puskesmas. Buletin Penelitian Kesehatan, Vol. 46, No. 2, Juni 2018 : 97 -108

Hidayat AA, 2007. Metode Penelitian Kebidanan Teknik analisis Data. Jakarta: Salemba

Imbalo S. Pohan 2006. Jaminan Mutu Layanan Kesehatan. Jakarta: EGC.

Lukman dan Sugiyanto. 2001. Manajemen Keuangan Perusahaan. PT. Raja Grafindo Indonesia, Jakarta.

Mufdlilah. 2009. Prosedur Asuhan Kebidanan Ibu Hamil. Jogjakarta : Nuha Medika.

Notoatmodjo, S, 2007, Kesehatan Masyarakat, Rineka Cipta, Jakarta

Notoatmojo, Soekidjo Dr. 2010. Metodologi Penelitian Kesehatan. Jakarta: Rineka Cipta.

Prawirohardjo, Sarwono.2008. Ilmu Kebidanan. Jakarta : Bina Nusantara.

Suharsimi Arikunto.2010. Prosedur Penelitian Suatu Pendekatan Praktik.Jakarta : Rineka Cipta

Sugiyono.2010. Metode penelitian Kuantitatif Kualitatif dan RND. Bandung: Alfabeta

Tjiptono. F. 2005. Service Quality and Satisfaction.Andi Offset: Yogyakarta.

Wiknjosastro Prawirohardjo. 2005. Ilmu Kebidanan. Yogyakarta: Yayasan Bina Pustaka. 